\title{
The clinical implication and molecular mechanism of preferential IL-4 production by modified glycolipid-stimulated NKT cells
}

\author{
Shinji Oki, Asako Chiba, Takashi Yamamura, and Sachiko Miyake \\ Department of Immunology, National Institute of Neuroscience, National Center for Neuroscience and Psychiatry, Tokyo, Japan.
}

\begin{abstract}
$\mathrm{OCH}$, a sphingosine-truncated analog of $\alpha$-galactosylceramide ( $\alpha \mathrm{GC}$ ), is a potential therapeutic reagent for a variety of Th1-mediated autoimmune diseases through its selective induction of Th2 cytokines from natural killer T (NKT) cells. We demonstrate here that the NKT cell production of IFN- $\gamma$ is more susceptible to the sphingosine length of glycolipid ligand than that of IL-4 and that the length of the sphingosine chain determines the duration of NKT cell stimulation by CD1d-associated glycolipids. Furthermore, IFN- $\gamma$ production by NKT cells requires longer $T$ cell receptor stimulation than is required for IL-4 production by NKT cells stimulated either with immobilized mAb to CD3 or with immobilized " $\alpha$ GC-loaded" CD1d molecules. Interestingly, transcription of IFN- $\gamma$ but not that of $I L-4$ was sensitive to cycloheximide treatment, indicating the intrinsic involvement of de novo protein synthesis for IFN- $\gamma$ production by NKT cells. Finally, we determined $c$-Rel was preferentially transcribed in $\alpha \mathrm{GC}$-stimulated but not in OCH-stimulated NKT cells and was essential for IFN- $\gamma$ production by activated NKT cells. Given the dominant immune regulation by the remarkable cytokine production of ligand-stimulated NKT cells in vivo, in comparison with that of (antigen-specific) T cells or NK cells, the current study confirms $\mathrm{OCH}$ as a likely therapeutic reagent for use against Th1-mediated autoimmune diseases and provides a novel clue for the design of drugs targeting NKT cells.
\end{abstract}

\section{Introduction}

Natural killer T (NKT) cells are a unique subset of T lymphocytes that coexpress the $\alpha / \beta$ T cell receptor (TCR) along with markers of the NK lineage such as NK1.1, CD122, and various Ly49 molecules. Most NKT cells express an invariant TCR $\alpha$ chain composed of V $\alpha 14-\mathrm{J} \alpha 281$ segments in mice and V $\alpha 24-\mathrm{J} \alpha \mathrm{Q}$ segments in humans associated with a restricted set of $V \beta$ genes $(1,2)$. Unlike conventional $T$ cells, which recognize peptides presented by MHC molecules, NKT cells recognize glycolipid antigens such as $\alpha$-galactosylceramide $(\alpha \mathrm{GC})$ in the context of a nonpolymorphic MHC class I-like molecule, CD1d (3-5). After being stimulated by a ligand, NKT cells rapidly affect the functions of neighboring cell populations such as T cells, NK cells, B cells, and dendritic cells $(6,7)$. The various functions of NKT cells are mediated mainly by a rapid release of large amounts of cytokines, including IL-4 and IFN- $\gamma$. Whereas IFN- $\gamma$ provides help for the Th 1 responses required for defending against various pathogens and tumors, IL-4 controls the initiation of Th2 responses and has been shown to inhibit Th1-mediated autoimmune responses involved in experimental autoimmune encephalomyelitis (EAE), collagen-induced arthritis (CIA), and type 1 diabetes in NOD mice.

Given the exceptional ability of NKT cells to secrete regulatory cytokines in comparison with that of T cells or NK cells after primary stimulation, we have explored the possibility that

Nonstandard abbreviations used: altered glycolipid ligand (AGL); altered peptide ligand (APL); CD28 responsive element (CD28RE); collagen-induced arthritis (CIA); c-Rel lacking C-terminal transactivation domain (c-Rel $\Delta \mathrm{TA})$; cycloheximide (CHX); cyclosporin A (CsA); experimental autoimmune encephalomyelitis (EAE); $\alpha$-galactosylceramide $(\alpha G C)$; natural killer T (NKT); nuclear factor of activated T cell (NF-AT); phycoerythrin (PE); $\mathrm{T}$ cell receptor (TCR).

Conflict of interest: The authors have declared that no conflict of interest exists.

Citation for this article: J. Clin. Invest. 113:1631-1640 (2004).

doi:10.1172/JCI200420862. ligand stimulation of NKT cells may lead to the suppression of Th1-mediated autoimmune diseases. We have previously demonstrated that $\mathrm{OCH}$, a sphingosine-truncated analog of $\alpha \mathrm{GC}$, preferentially induces Th2 cytokines from NKT cells and that administration of $\mathrm{OCH}$ suppresses EAE and CIA by inducing a Th2 bias in autoantigen-reactive T cells $(8,9)$. However, the molecular mechanism accounting for the unique property of $\mathrm{OCH}$ to selectively induce IL-4 has not been clarified yet.

In this study, we used various stimuli, including the prototypic ligand $\alpha \mathrm{GC}$ and its derivatives such as $\mathrm{OCH}$, to investigate the molecular basis of the differential production of IL- 4 and IFN- $\gamma$ by NKT cells. We found that $\mathrm{OCH}$, due to its truncated lipid chain, was less stable in binding the CD1d molecule than was $\alpha \mathrm{GC}$ and exerted short-lived stimulation on NKT cells. IFN- $\gamma$ production by NKT cells required longer TCR stimulation than was required for IL-4 production and de novo protein synthesis. $c$-Rel was preferentially transcribed in $\alpha$ GC-stimulated, but not in OCH-stimulated NKT cells and was shown to regulate IFN- $\gamma$ production by NKT cells. Taken together, these results indicate that sustained TCR stimulation and concomitant c-Rel expression by $\alpha \mathrm{GC}$ leads to the production of IFN- $\gamma$, whereas short-term activation and marginal $c$-Rel transcription by OCH results in preferential production of IL-4 by NKT cells.

\section{Methods}

Mice. C57BL/6 (B6) mice were purchased from CLEA Laboratory Animal Corp. (Tokyo, Japan). MHC class II-deficient I-A $\boldsymbol{A}^{\mathrm{b}} \boldsymbol{\beta}^{-/-}$mice were purchased from Taconic (Germantown, New York, USA). All animals were kept under specific pathogen-free conditions and were used at 7-10 weeks of age. Animal care and use were in accordance with institutional guidelines.

Cell lines, antibodies, plasmids, and reagents. The NKT cell hybridoma (N38.2C12) (10) was a generous gift from K. Hayakawa (Fox Chase Cancer Center, Philadelphia, Pennsylvania, USA) and NS0-derived 
plasmacytoma cell lines expressing the Kb tail mutant of CD1d (11) were kindly provided by S. Joyce (Vanderbilt University, Nashville, Tennessee, USA). Cells were maintained in RPMI 1640 medium supplemented with $10 \%$ FCS, $2 \mathrm{mM} \mathrm{L-glutamine,} 100 \mathrm{U} / \mathrm{ml}$ penicillin/ streptomycin, $2 \mathrm{mM}$ sodium pyruvate, and $50 \mu \mathrm{M} \beta$-mercaptoethanol (complete medium). Phycoerythrin (PE)-labeled mAb to NK1.1 (PK136), peridinine chlorophyll protein/cyanine 5.5 -labeled mAb to CD3 (2C11), and recombinant soluble dimeric human CD1d:Ig fusion protein (DimerX I) were from BD PharMingen (San Diego, California, USA). For some experiments mAb's to NK1.1 (PK136) and CD3 (2C11) were conjugated with FITC. Polyclonal antibody to asialo $\mathrm{GM}_{1}$ was purchased from WAKO Chemicals (Osaka, Japan). The pRc/CMV-c-Rel expression plasmid (12) was a generous gift from Grundström (Umeå University, Umeå, Sweden). The open reading frame of c-Rel cDNA was amplified by PCR and cloned into the retroviral $\mathrm{pMIG}(\mathrm{W})$ vector. The forward primer containing the XhoI recognition site was 5'-GACTCTCGAGATGGCCTCGAGTGGATATAA-3' and the reverse primers used for wild-type c-Rel or the dominant negative mutant c-Rel $\Delta$ TA containing EcoRI recognition sites were 5'-GACTGAATTCTTATATTTTAAAAAAACCATATGTGAAGG-3' and 5'-GACTGAATTCTTAACTCGAGATGGACCCGCATG-3', respectively. The retroviral vector (pMIG) and packaging vector ( $\mathrm{pCL}-\mathrm{Eco}$ ) were kindly provided by L. Van Parijs (Massachusetts Institute of Technology, Cambridge, Massachusetts, USA). Cyclosporin A (CsA) and cycloheximide (CHX) were from SigmaAldrich (St. Louis, Missouri, USA). All glycolipids were prepared as described in the Supplemental Methods (supplemental material available at http://www.jci.org/cgi/content/full/113/11/1631/ DC1). The glycolipids were solubilized in DMSO $(100 \mu \mathrm{g} / \mathrm{ml})$ and were stored at $-20^{\circ} \mathrm{C}$ until use.

Kinetic analysis of glycolipid stability on CD1d molecules. The kinetic analysis of glycolipid stability on CD1d molecules was performed as described previously with slight modifications (13). In brief, the NKT hybridoma was preincubated with $4 \mu \mathrm{M}$ Fura red and $2 \mu \mathrm{M}$ Fluo-4 (Molecular Probes, Eugene, Oregon, USA) at room temperature for 45 minutes, washed with RPMI 1640 medium containing $2 \%$ FCS (assay media), and resuspended in assay media. For determination of the optimal time for glycolipid loading onto CD1 $\mathrm{d}^{+}$ APCs, kinetic analysis was conducted using either $\alpha \mathrm{GC}$ or OCH. According to the data obtained in Figure $2 \mathrm{C}, \mathrm{CD} 1 \mathrm{~d}^{+}$APCs were pulsed with glycolipids $(100 \mathrm{ng} / \mathrm{ml})$ for 30 minutes. Then, cells were washed and resuspended in assay media. Glycolipid-pulsed APCs were harvested every 15 minutes after resuspension, mixed with NKT cells, and subjected to centrifugation in a table-top centrifuge $(2,000 \mathrm{~g})$ for 60 seconds. Cells were then resuspended briefly and analyzed for calcium influx into NKT hybridoma cells by flow cytometry (EPICS XL; Beckman Coulter, Tokyo, Japan). Activation was expressed as the percentage of Fura-red- and Fluo-4stained cells in a high-FL1, low-FL4 gate.

In vivo glycolipid treatment and microarray analysis. Mice were injected intraperitoneally with $0.2 \mathrm{ml}$ PBS containing $0.1 \mathrm{mg}$ anti-asialo $\mathrm{GM}_{1} \mathrm{Ab}$. Forty hours after injection, mice were injected intraperitoneally with $\alpha \mathrm{GC}, \mathrm{OCH}(100 \mu \mathrm{g} / \mathrm{kg})$, or control vehicle in $0.2 \mathrm{ml}$ PBS. After the indicated time point, liver mononuclear cells or spleen cells were harvested and NKT cells were purified with the AUTOMACS cell purification system using FITC-conjugated mAb to NK1.1 (PK136) and anti-FITC microbeads (Miltenyi Biotech GmbH, Bergisch Gladbach, Germany). The purity of NKT cells in the untreated samples and in the samples treated for 1.5 hours was more than $90 \%$. The purity of the liver-derived samples and spleen-derived samples treated for 12 hours was more than $80 \%$ and 74\%, respectively. Total RNA isolation with the RNeasy Mini Kit (Qiagen, Chatsworth, California, USA) and whole-microarray procedures using U74Av2 arrays (GeneChip System; Affymetrix, Santa Clara, California, USA) were done according to the manufacturers' instructions. From data image files, gene transcript levels were determined using algorithms in the Gene Chip Analysis Suit software (Affymetrix). Each probe was assigned a "call" of present (expressed) or absent (not expressed) using the Affymetrix decision matrix. Genes were considered to be differentially expressed when (a) expression changed at least threefold in the case of liver NKT-derived samples or twofold in the case of spleen NKT-derived samples compared with the expression in the negative control and (b) increased gene expression included at least one "present call."

In vitro stimulation. Liver mononuclear cells were isolated from B6 mice by Percoll density gradient centrifugation and were stained with PE-NK1.1 and FITC-CD3 mAb's. The CD $3^{+} \mathrm{NK} 1.1^{+}$cells and $\mathrm{CD}^{+} \mathrm{NK} 1.1^{-}$cells were sorted with an EPICS ALTRA Cell Sorting System (Beckman Coulter). The purity of the sorted cells was more than $95 \%$. Sorted cells were suspended in RPMI 1640 medium supplemented with $50 \mu \mathrm{M} 2$-mercaptoethanol, $2 \mathrm{mM}$ L-glutamine, 100 $\mathrm{U} / \mathrm{ml}$ penicillin and streptomycin, and $10 \% \mathrm{FCS}$ and were stimulated with immobilized $m A b$ to $C D 3$. Incorporation of $\left[{ }^{3} \mathrm{H}\right]$ thymidine $(1 \mu \mathrm{Ci} /$ well) for the final 16 hours of the culture was analyzed with a $\beta-1205$ counter (Pharmacia, Uppsala, Sweden). We measured the content of cytokines in the culture supernatants by ELISA. For quantitative PCR analysis, we harvested the cells after stimulation with glycolipid to prepare total RNA. Glycolipid stimulation of spleen cells in vitro was done similarly except that $1 \%$ syngeneic mouse serum was used instead of FCS. In some experiments, plates were coated with DimerX I ( $1 \mu \mathrm{g}$ in $50 \mu \mathrm{l}$ PBS per well) for 16 hours. After plates were washed extensively with PBS, glycolipids (100-200 ng in $50 \mu \mathrm{l}$ PBS per well) were added, followed by incubation for another 24 hours. Then, NKT cells were added and cytokine production was analyzed after 72 hours of incubation.

Real-time PCR to monitor gene expression. Real-time PCR was conducted using a Light Cycler-FastStart DNA Master SYBR Green I kit (Roche Diagnostics GmbH, Mannheim, Germany) according to the manufacturer's specifications using $4 \mathrm{mM} \mathrm{MgCl}_{2}$ and $1 \mathrm{pM}$ primers. Values for each gene were normalized to those of a housekeeping gene (GAPDH) before the "fold change" was calculated (using crossing point values) to adjust for variations between different samples. Primers used for the analysis of gene expression are described in Supplemental Methods.

ELISA. For evaluation of cytokine production by NKT cells, sorted liver $\mathrm{CD}^{+} \mathrm{NK} 1.1^{+} \mathrm{NKT}$ cells were stimulated with immobilized $\mathrm{mAb}$ to $\mathrm{CD} 3$ in complete medium. The level of cytokine production in cell culture supernatants or in serum was determined by standard sandwich ELISA using purified and biotinylated mAb sets and standards from BD PharMingen. After the addition of a substrate, the reaction was evaluated using a Microplate reader (BioRad).

Retroviral infection of NKT cells. The 293T cells were maintained in DMEM supplemented with 10\% FCS, 2 mM L-glutamine, 100 $\mathrm{U} / \mathrm{ml}$ penicillin/streptomycin, $2 \mathrm{mM}$ sodium pyruvate, and $50 \mu \mathrm{M}$ $\beta$-mercaptoethanol. Liver mononuclear cells were purified and cultured in complete medium supplemented with IL-2 (200 U/ml) for 24-48 hours. Cells were infected with retrovirus prepared by cotransfection of PMIG retroviral vector and PCL-Eco packaging vector into $293 \mathrm{~T}$ cells. Cells were cultured in complete medium containing IL-2 and IL-15 (50 ng/ml) continuously for 3 days, and 

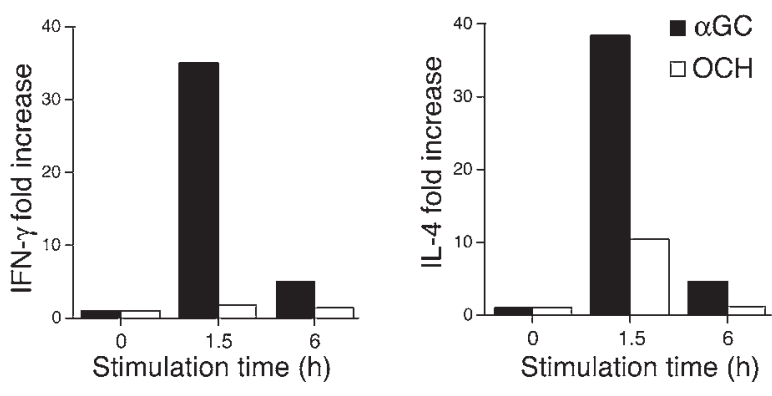

\section{Figure 1}

Transcriptional upregulation of cytokine genes by NKT cells stimulated with glycolipids in vivo. B6 mice were injected intraperitoneally with $\alpha \mathrm{GC}$ or $\mathrm{OCH}(100 \mu \mathrm{g} / \mathrm{kg})$, and liver NKT cells were isolated at the indicated time point. Total RNA was extracted and analyzed for cytokine mRNA by quantitative RT-PCR as described in Methods. Data are presented as "fold induction" of cytokine mRNA after glycolipid treatment. The amount of mRNA in NKT cells derived from untreated animals was defined as 1.

GFP-positive NKT cells were sorted and stimulated with immobilized $\mathrm{mAb}$ to $\mathrm{CD} 3$ for 48 hours. Culture supernatants were subjected to evaluation of cytokine production by ELISA.

\section{Results}

Preferential IL-4 production by OCH-stimulated NKT cells. The suppression of EAE by OCH was found to be associated with a Th2 bias of autoimmune T cells mediated by IL-4 produced by NKT cells (9). To confirm the primary involvement of NKT cells in the Th2 bias seen in the $\mathrm{OCH}$ treatment, we purified $\mathrm{CD}^{+} \mathrm{NK} 1.1^{+} \mathrm{NKT}$ cells from $\mathrm{B} 6$ mice treated in vivo with $\alpha \mathrm{GC}$ or $\mathrm{OCH}$ and measured the transcription of cytokine genes by quantitative RT-PCR. As shown in Figure 1, treatment with $\alpha \mathrm{GC}$ greatly increased the expression of both IFN- $\gamma$ and IL- 4 at 1.5 hours after injection, whereas $\mathrm{OCH}$ induced a selective increase in IL-4 expression. When the IL-4/IFN- $\gamma$ ratio was used for evaluating the Th1/Th2 balance, the NKT cells, isolated at 1.5 hours after injection of $\mathrm{OCH}$ were distinctly biased toward Th2 (Table 1). These results indicate that $\mathrm{OCH}$ is a selective inducer of rapid IL-4 production by NKT cells when administered in vivo.

Lipid chain length and cytokine production. Comparison of the structural difference between $\mathrm{OCH}$ and $\alpha \mathrm{GC}$ (Figure $2 \mathrm{~A}$ ) raised the possibility that the lipid chain length of the glycolipid ligand may influence the cytokine profile of glycolipid-treated NKT cells. We compared $\alpha \mathrm{GC}$ and $\mathrm{OCH}$ as well as newly synthesized analogs F-2/S-3 and F-2/S-7, which bear lipids of intermediate length (Figure 2A), for their ability to induce cytokine production by splenocytes. There was good correlation between the lipid tail length of each glycolipid and its ability to induce IFN- $\gamma$ from the splenocytes, and a larger amount of IFN- $\gamma$ was released into the supernatants after stimulation with the glycolipids with the longer sphingosine chain (Figure 2B, right). Regarding the ability to stimulate IL-4 production, the differences among $\mathrm{OCH}$, F-2/S-3 and F-2/S-7 were less clear, as shown by IFN- $\gamma$ induction. Similar results were obtained with liver mononuclear cells as responder cells (see Supplemental Figure 1). These results indicate that cytokine production by NKT cells, in particular IFN- $\gamma$ production, is greatly influenced by lipid chain truncation of the glycolipid.

Differential half-life of NKT cell stimulation by CD1d-associated glycolipids. It is believed that the two lipid tails of the glycolipids (sphingosine base and fatty acyl chain) would be accommodated by the highly hydrophobic binding grooves of CD1d. To verify the hypothesis that the functional properties of each glycolipid may be determined by the stability of its binding to CD1d molecules, we evaluated the half-life of these glycolipids on CD1d molecules by estimating calcium influx into NKT hybridoma cells as described previously (13). To exclude the possible involvement of endosomal/lysosomal sorting in this assay, we used APCs expressing a CD1d mutant $(\mathrm{Kb}$ tail) that lacks the endosomal/lysosomal targeting signal (11). The cells express both $\beta_{2} \mathrm{~m}$ and sCD1d1 fused to the transmembrane and cytosolic tail sequence of $\mathrm{H}-2 \mathrm{~K}^{\mathrm{b}}$ at the carboxyl terminus and could bind to glycolipids such as $\alpha \mathrm{GC}$ or $\mathrm{OCH}$ without their internalization and following endosomal/lysosomal sorting. Based on the kinetic analysis data for glycolipid loading efficiency shown in Figure 2C, we pulsed CD1 $\mathrm{d}^{+}$APCs with glycolipids for 30 minutes.

Figure $2 \mathrm{D}$ shows that $\mathrm{OCH}$ was rapidly released from the CD1d molecule. A $30 \%$ reduction in calcium influx was observed after 15 minutes of incubation and only $25 \%$ of the initial amount of glycolipid remained after 60 minutes of incubation. In contrast, $\alpha \mathrm{GC}$ was not released from CD1d molecule in the first 15 minutes and more than $50 \%$ of the initial amount of glycolipid remained after 60 minutes of incubation. F-2/S-3 and F-2/S-7 showed intermediate levels of release from CD1d molecule. These results support the idea that a glycolipid with a shorter sphingosine chain has a shorter half-life for NKT cell stimulation because of less-stable association with the CD1d molecule.

Kinetic analysis of cytokine production by activated NKT cells. Previous in vivo studies demonstrated that injection of $\alpha \mathrm{GC}$ into $\mathrm{B} 6$ mice can induce a rapid and transient elevation of the serum IL-4 level and a delayed and persistent rise in IFN- $\gamma(9,14)$, suggesting that there is an intrinsic difference in kinetics for the production of IL- 4 and IFN- $\gamma$ by NKT cells. To address this issue further, we sorted $\mathrm{CD} 3^{+} \mathrm{NK} 1.1^{+}$ NKT cells, and conventional $\mathrm{CD}^{+} \mathrm{NK} 1.1^{-} \mathrm{T}$ cells as a control, from liver lymphocytes and stimulated the sorted cells with immobilized $\mathrm{mAb}$ to CD3 for various periods of time. The cells were then incubated at rest without further stimulation and culture supernatants were harvested at 72 hours after initiation of the TCR stimulation. We found that TCR stimulation of NKT cells for as little as 2 hours could induce detectable IL-4 in the supernatant (Figure 3A, center). The amount of IL-4 in the supernatant rapidly increased in proportion to the duration of TCR stimulation (Figure 3A, center). In contrast, production of IFN- $\gamma$ by NKT cells required at least 3 hours of TCR stimulation and gradually increased corresponding to the duration of TCR stimulation (Figure 3A, right). Conventional T cells required longer TCR stimulation for efficient cytokine production. We repeatedly confirmed that IFN- $\gamma$ production by NKT cells required initial stimulation that was 1-2 hours longer and showed a slower accumulation than that of IL-4 production in this experimen-

\section{Table 1}

Transcriptional upregulation of cytokine genes by NKT cells stimulated with glycolipids in vivo

\begin{tabular}{|c|c|c|c|c|}
\hline Stimulus & Time & $I F N-\gamma$ & IL-4 & Ratio (IL-4/IFN- $\gamma$ ) \\
\hline \multirow[t]{2}{*}{$\alpha G C$} & $1.5 \mathrm{~h}$ & 35.0 & 38.3 & 1.09 \\
\hline & $6 \mathrm{~h}$ & 5.0 & 4.6 & 0.92 \\
\hline \multirow[t]{2}{*}{$\mathrm{OCH}$} & $1.5 \mathrm{~h}$ & 1.8 & 10.3 & 5.58 \\
\hline & $6 \mathrm{~h}$ & 1.5 & 1.1 & 0.72 \\
\hline
\end{tabular}

The relative amounts of transcripts of IFN- $\gamma$ and $I L-4$ obtained from the experiment shown in Figure 1 are presented as "fold induction" relative to that of NKT cell-derived samples from untreated animals. 
A

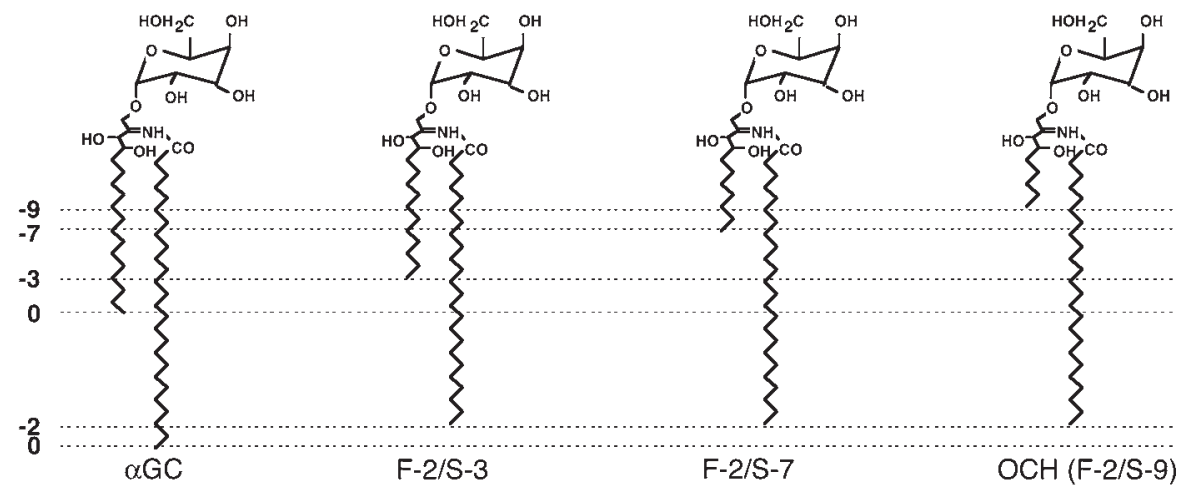

B
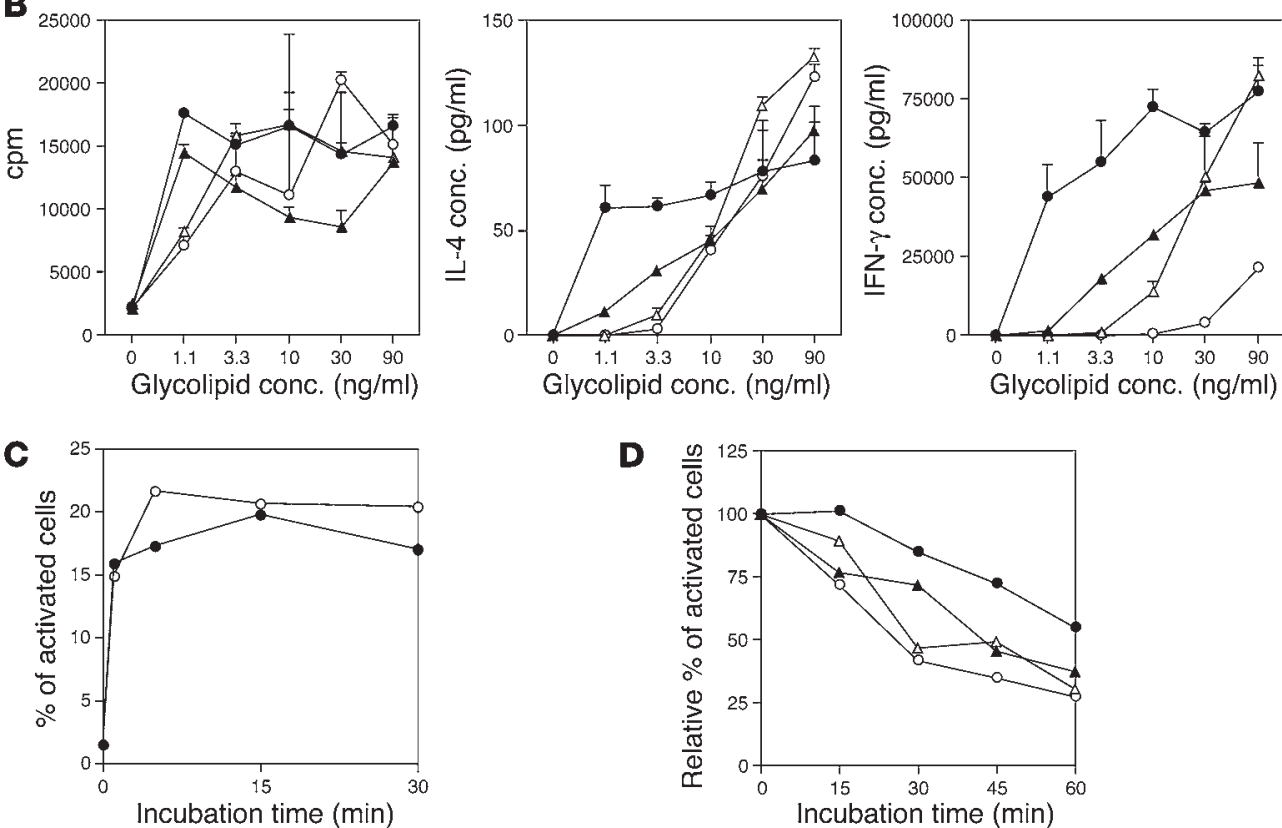

Figure 2

Differential properties of structurally distinct glycolipid derivatives. (A) Structures of $\alpha \mathrm{GC}, \mathrm{OCH}$, and two other glycolipid ligands for NKT cells. F-2/S-3 has a truncation of two hydrocarbons in the fatty acyl chain $(F)$ and of three hydrocarbons in the sphingosine chain (S) in comparison with $\alpha \mathrm{GC}$. $\mathrm{OCH}$ can be called F-2/S-9 accordingly. The numbers of truncated hydrocarbons in either lipid chain are shown along the left margin as negative integers. (B) Effect of $\alpha \mathrm{GC}, \mathrm{OCH}$, and other glycolipids on proliferation and cytokine production of splenocytes. Splenocytes were stimulated with various concentrations (conc.) of $\alpha \mathrm{GC}$ (filled circles), $\mathrm{OCH}$ (open circles), F-2/S-3 (filled triangles), or F-2/S-7 (open triangles) for 72 hours. Incorporation of $\left[{ }^{3} \mathrm{H}\right]$ thymidine $(1 \mu \mathrm{Ci} /$ well) during the final 16 hours of the culture was assessed (left), and IL-4 (center) or IFN- $\gamma$ (right) in the supernatants was measured by ELISA. (C) Kinetic analysis of the loading of $\alpha$ GC (filled circles) or OCH (open circles) onto CD1d+ APCs. See Methods for details. One experiment representative of two independent experiments with similar results is shown. (D) Calcium influx into NKT hybridoma cells after coculture with CD1d ${ }^{+}$APCs pulsed with $\alpha \mathrm{GC}, \mathrm{OCH}, \mathrm{F}-2 / \mathrm{S}-3$, or F-2/S-7. Data are presented as the activity remaining when the respective activity of glycolipid-loaded APCs for activation of the NKT cell hybridoma at time 0 was defined as $100 \%$. Data are representative of three experiments with similar results.

tal setting. A similar kinetic difference was also observed when we used spleen-derived NKT cells (data not shown). These results indicate that NKT cells could produce IL-4 after a shorter period of TCR stimulation than is required for IFN- $\gamma$ production.

To exclude the possibility that a qualitatively different CD1d complex with either $\alpha \mathrm{GC}$ or $\mathrm{OCH}$ may bind with altered affinity to the TCR, we stimulated NKT cells with plate-bound $\alpha \mathrm{GC}-\mathrm{CD} 1 \mathrm{~d}$ complexes instead of $\mathrm{mAb}$ to $\mathrm{CD} 3$ for the periods of time indicated in Figure 3B. Consistent with the previous results obtained with anti-CD3 stimulation, the level of IL-4 in the culture supernatant was increased after shorter periods of incubation. In contrast, IFN- $\gamma$ was efficiently produced after longer incubation, showing that the short pulse of NKT cells with plate-bound $\alpha$ GC-CD1d complexes could recapitulate the $\mathrm{OCH}$ phenotype. These results demonstrate that the timing of the CD1d-lipid interaction rather than the "shape" of the OCH-CD1d complex is the decisive factor in controlling polarization of cytokine production by NKT cells.

Differential transcriptional properties of cytokine genes. To clarify the molecular basis for different kinetics of cytokine production by activated NKT cells, we next examined the effects of CsA or CHX on the NKT cell responses. Without any inhibitors, IL-4 production was more rapid and had a higher rate than IFN- $\gamma$ production (Figure 3C), confirming the kinetic difference required for induction of each cytokine shown in Figure 3A. Production of both IL-4 

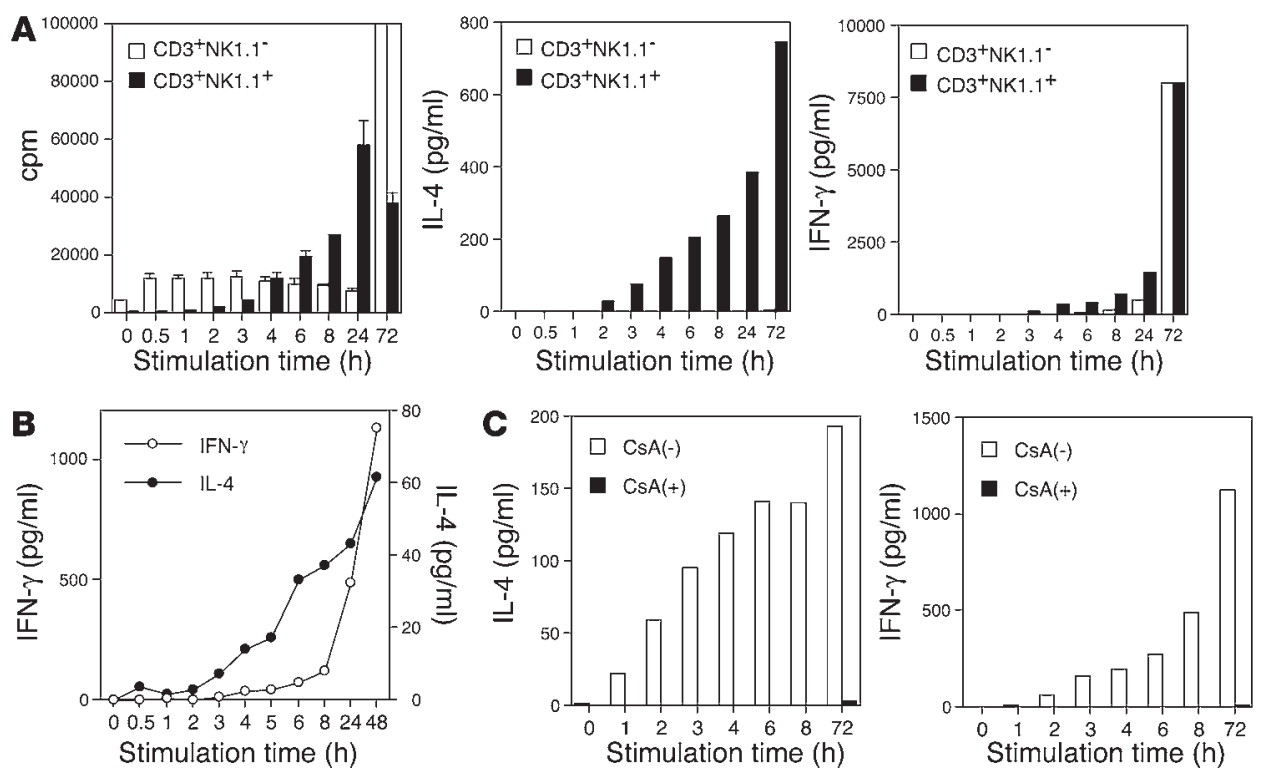

Figure 3

Kinetic analysis of NKT cell activation and cytokine production after glycolipid stimulation. (A) Differential production of IFN- $\gamma$ and IL-4 by activated NKT cells. CD3+NK1.1+ NKT cells and conventional CD3+NK1.1$\mathrm{T}$ cells were purified from liver mononuclear cells by cell sorting. The sorted cells were stimulated with immobilized $\mathrm{mAb}$ to CD3 for the time indicated on the $x$ axis and were then removed and recultured on a fresh culture plate without anti-CD3 stimulation for up to 72 hours from the start of the anti-CD3 stimulation. Incorporation of $\left[{ }^{3} \mathrm{H}\right]$ thymidine $(1 \mu \mathrm{Ci} /$ well) during the final 16 hours of the culture was assessed (left), and culture supernatants were analyzed for the production of IL-4 (center) and IFN- $\gamma$ (right) by ELISA. One experiment representative of three independent experiments with similar results is shown. (B) NKT cells purified from liver mononuclear cells were stimulated with plates coated with DimerX I loaded with $\alpha \mathrm{GC}$ and were analyzed as shown in A. (C) NKT cells purified from liver mononuclear cells were stimulated as shown in $\mathbf{A}$ in the presence $[\mathrm{CsA}(+)]$ or absence $[\operatorname{CsA}(-)]$ of $\operatorname{CsA}(1 \mu \mathrm{g} / \mathrm{ml})$. Culture supernatants were analyzed for the production of IL- 4 and IFN- $\gamma$ by ELISA.

and IFN- $\gamma$ after TCR stimulation, however, was almost completely inhibited by pretreatment of NKT cells with CsA.

Similarly, CsA abolished the transcriptional activation of $I L-4$ and IFN- $\gamma$ genes in activated NKT cells (Figure 4A), indicating that TCR signal-induced activation of nuclear factor of activated T cell (NF-AT) is indispensable for the production of both cytokines by NKT cells. Meanwhile, transcription of these cytokine genes showed different sensitivities to CHX treatment (Figure 4A). Although transcriptional activation of $I L-4$ was barely affected by CHX treatment, transcription of IFN- $\gamma$ gene was almost completely blocked after treatment with CHX. These results indicate that transcriptional activation of $I F N-\gamma$, but not that of $I L-4$, requires de novo protein synthesis.

Next, we analyzed the sensitivities of other cytokine genes to CsA and CHX treatment (15-17). As shown in Figure 4B, transcriptional activation of all cytokine genes tested was completely blocked by pretreatment of NKT cells with CsA. Interestingly, transcription of the $I L-2$ gene and GM-CSF gene were blocked by CHX treatment. In contrast, transcriptional activation of TNF- $\alpha$ was resistant to $\mathrm{CHX}$ treatment. These results indicate that cytokines produced by NKT cells could be divided into two groups based on their dependence on de novo protein synthesis.

Selective c-Rel induction after stimulation with $\alpha$ GC. Although NKT cells secrete a large number of cytokines upon stimulation, the regulatory mechanisms for the expression of each cytokine are still poorly understood. The susceptibility of IFN- $\gamma$ production to $\mathrm{CHX}$ indicates that some newly synthesized protein(s) would promote specific tran- scription of the IFN- $\gamma$ gene in NKT cells. To identify the protein responsible for $\alpha G C$-induced transcription of the IFN- $\gamma$ gene, we purified NKT cells from glycolipid-administered $\mathrm{I}-\mathrm{A}^{\mathrm{b}} \boldsymbol{\beta}$-deficient mice, which have two- to threefold higher numbers of NKT cells in the liver and the spleen than do wild-type B6 mice (18), and assessed NKT cell-derived total RNA by microarray analysis. As shown in Table 2, a number of cytokines and chemokines were differentially expressed after in vivo treatment with either $\alpha \mathrm{GC}$ or $\mathrm{OCH}$. It is noteworthy, however, that significant induction of IFN- $\gamma$ transcription was observed only in aGC-treated samples, not in OCHtreated samples. Overall, the data obtained correlated well with previous results showing that $\mathrm{OCH}$ is a selective inducer of IL-4 production from NKT cells (9). There was no transcriptional upregulation of cytokines genes such as the $I F N-\gamma$ and $I L-4$ genes 12 hours after treatment with either glycolipid, indicating that NKT cells have undergone quiescence at this time point in the context of transcriptional upregulation of cytokine genes, although some genes are still upregulated.

Through analyzing the microarray data, we identified the protooncogene $c$-Rel, a member of the NF- $\mathrm{KB}$ family of transcription factors, as a candidate molecule that may play a role in the IFN- $\gamma$ transcription. As shown in Figure 5A, $c$-Rel was inducibly expressed in NKT cells 1.5 hours after stimulation with $\alpha \mathrm{GC}$. In contrast, $\mathrm{OCH}$ treatment did not induce $c$-Rel transcription (Figure 5A).

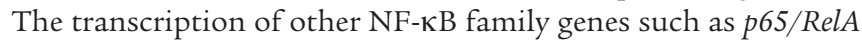
and $\mathrm{Rel} B$ was not upregulated after treatment with $\alpha \mathrm{GC}$ or $\mathrm{OCH}$. Real-time PCR analysis also confirmed the selective induction of $c$-Rel after $\alpha \mathrm{GC}$ stimulation (Figure 5B). CsA treatment inhibited $c$-Rel transcription, but CHX did not (Figure 5C), indicating that the inducible transcription of c-Rel is directly controlled by TCR signal-mediated activation of the NF-AT (19).

It is already known that c-Rel serves as a pivotal transcription factor for the Th1 response that would directly induce IFN- $\gamma$ production in conventional T cells (20). However, very little is known about the function of this protooncogene in NKT cells during TCR-mediated activation. We therefore conducted time course analysis for transcriptional activation of $c$-Rel in parallel with $I L-4$ and $I F N-\gamma$. We stimulated NKT cells with immobilized mAb to CD3 for 30-100 minutes and then cultured them without further stimulation for a total of 120 minutes. As shown in Figure 5D, IFN- $\gamma$ expression was slightly downregulated in the first 90 minutes of TCR stimulation and was significantly upregulated when the cells were stimulated for 100 minutes. Interestingly, we found that the kinetics of $c$-Rel transcription were similar to those of IFN- $\gamma$ transcription (Figure 5D, right). In contrast, transcrip- 

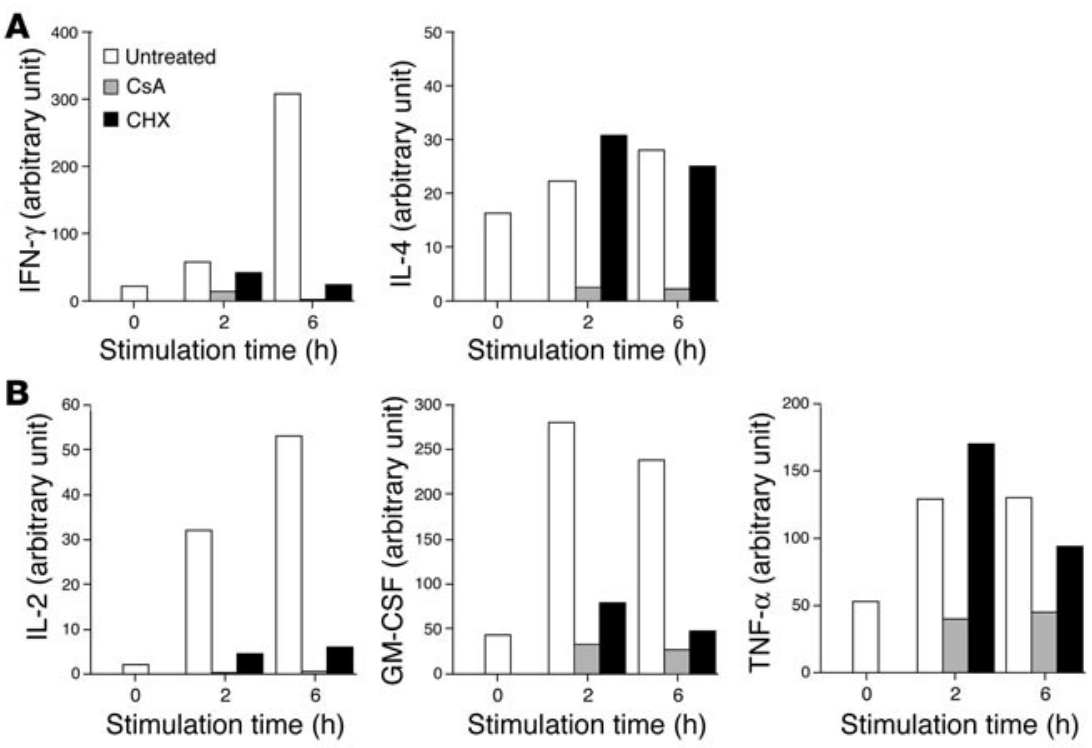

\section{Figure 4}

Differential sensitivity to CsA and $\mathrm{CHX}$ for transcriptional upregulation of IFN- $\gamma, I L-4$, and other cytokines. (A) Sorted NKT cells were pretreated with CsA $(1 \mu \mathrm{g} / \mathrm{ml})$ or with $\mathrm{CHX}(10 \mu \mathrm{g} / \mathrm{ml})$ or without either reagent for 10 minutes and were then stimulated with immobilized $\mathrm{mAb}$ to CD3 for the indicated periods of time. Total RNA was extracted from each sample and analyzed for the relative amount of transcript of IFN- $\gamma$ or IL-4. Data are presented as the amount of transcript in each sample relative to GAPDH. (B) Sorted NKT cells were pretreated with CsA $(1 \mu \mathrm{g} / \mathrm{ml})$ or with $\mathrm{CHX}(10 \mu \mathrm{g} / \mathrm{ml})$ or without either reagent as shown in A. Total RNA was extracted from each sample and was analyzed for the relative amount of transcripts of IL-2, GM$C S F$, or $T N F-\alpha$. Data are presented as the relative amount of transcript in each sample. tional activation of $I L-4$ became evident 30 minutes after TCR stimulation and the transcript accumulated gradually in proportion to the duration of TCR stimulation. This result further confirmed that NKT cells require a longer TCR stimulus for IFN- $\gamma$ expression.

Transcription of IFN- $\gamma$ genes depends on c-Rel expression in NKT cells. To further investigate the functional involvement of c-Rel in the transcription of IFN- $\gamma$ gene in NKT cells, we next examined whether forced expression of wild-type c-Rel or of its loss-of-function mutant could affect IFN- $\gamma$ production by NKT cells. For this, we used bicistronic retroviral vectors expressing c-Rel along with GFP (pMIG/c-Rel) or a c-Rel dominant negative mutant that lacks the C-terminal transactivation domain but retains an intact Rel homology domain of c-Rel protein (pMIG/c-Rel $\Delta$ TA) (21) (Figure 6A). We infected liver-derived mononuclear cells with either retrovirus and stimulated sorted GFP-positive NKT cells with immobilized mAb to $\mathrm{CD} 3$ to analyze cytokine production. Retroviral transduction led to expression of GFP in approximately $10 \%$ of NKT cells (Figure 6B). Upon stimulation with mAb to CD3, GFP-positive cells from pMIG/ c-Rel-infected cultures showed slightly augmented IFN- $\gamma$ production compared with that of control pMIG-infected cells (Figure 6C). In contrast, GFP-positive cells from pMIG/c-Rel $\Delta$ TA-infected cultures secreted almost no IFN- $\gamma$ after TCR stimulation (Figure $6 \mathrm{C}$ ). These results demonstrate that inhibition of c-Rel function, via the introduction of a mutant form of $\mathrm{c}-\mathrm{Rel}$, abolishes IFN- $\gamma$ production and that functional c-Rel is important for effective production of IFN- $\gamma$ in activated NKT cells.

\section{Discussion}

In this study, we investigated the molecular mechanism for differential production of IFN- $\gamma$ and IL-4 by activated NKT cells through a comparative analysis using the prototypic NKT cell ligands $\alpha$ GC and $\mathrm{OCH}$. Treatment with $\alpha \mathrm{GC}$ induced expression of both IFN- $\gamma$ and IL-4 simultaneously, but OCH induced selective expression of IL-4 by NKT cells. Furthermore, we demonstrated that the CD1d-associated glycolipids with various lipid chain lengths showed different half-lives for NKT cell stimulation when applied in an endosome/lysosomeindependent manner and induced the differential cytokine production by NKT cells in a lipid length-dependent manner. Accordingly, we demonstrated that IFN- $\gamma$ production by NKT cells required lon- ger TCR stimulation than did IL-4 production and depended on de novo protein synthesis. An NF- $\mathrm{B}$ family transcription factor gene, the $c$-Rel gene, was inducibly transcribed in $\alpha \mathrm{GC}$-stimulated but not in OCH-stimulated NKT cells. Retroviral transduction of a loss-offunction mutant of c-Rel revealed the functional involvement of c-Rel in IFN- $\gamma$ production by ligand-activated NKT cells. These results have provided a new interpretation of NKT cell activation - that the duration of TCR stimulation is critically influenced by the stability of each glycolipid ligand on CD1d molecules, which leads to the differential cytokine production by NKT cells.

We have previously demonstrated that administration of $\mathrm{OCH}$ consistently suppresses the development of EAE by inducing a Th2 bias in autoimmune T cells and that this Th2 shift is probably mediated by selective IL-4 production by NKT cells in vivo (9). Here we directly evaluated the cytokine profile of OCH-stimulated NKT cells using quantitative PCR analysis. Consistent with the previous assumption, NKT cells stimulated with $\mathrm{OCH}$ induced rapid production of IL-4 but led to only marginal induction of IFN- $\gamma$, confirming the presumed mechanism for the effect of OCH on EAE and CIA. As the "fold induction" of IFN- $\gamma$ transcript after 1.5 hours of stimulation with $\alpha \mathrm{GC}$ in microarray analysis was relatively low (fivefold for liver NKT cells and fourfold for spleen NKT cells) compared with the in vivo data, there are several possibilities to explain these results. First, quiescent transcripts of IFN- $\gamma$ pre-existing in resting V $\alpha 14$-invariant NKT cells (22) may raise the baseline of signal intensity in samples from untreated animals, resulting in a relative decrease in "fold induction" after glycolipid treatment. Second, detection of IFN- $\gamma$ transcription in $\alpha \mathrm{GC}$-stimulated NKT cells might not be optimal, as injection of $\alpha \mathrm{GC}$ induced a rapid elevation in IL-4 with the peak value at 2 hours and a delayed and prolonged elevation in IFN- $\gamma$ in B6 mice (9). Third, $\alpha \mathrm{GC}$ treatment significantly induces transcription of CD154 (18.0-fold for $\alpha \mathrm{GC}$ vs. 5.4-fold for $\mathrm{OCH}$; data not shown), whose promoter has a functional NF-AT binding site and CD28 responsive element (CD28RE) $(23,24)$. Thus, augmented CD40/ CD154 interaction may induce IL-12 expression by APCs, resulting in additional IFN- $\gamma$ production (25). Finally, NKT cells are not necessarily the only source of IFN- $\gamma$ after in vivo stimulation with $\alpha \mathrm{GC}$. The "serial" production of IFN- $\gamma$ by NKT cells and NK cells has been demonstrated $(6,26)$. In particular, a C-glycoside analog of $\alpha \mathrm{GC}$ has 


\section{Table 2}

Differential gene expression patterns in $\alpha \mathrm{GC}$-treated and OCH-treated murine NKT cells

\begin{tabular}{|c|c|c|c|c|c|c|c|c|c|c|c|c|c|c|c|c|c|c|c|c|}
\hline \multirow{4}{*}{$\begin{array}{l}\text { Common } \\
\text { name }\end{array}$} & \multicolumn{11}{|c|}{ Liver CD3+NK1.1+ } & \multicolumn{9}{|c|}{ Spleen CD3+NK1.1+ } \\
\hline & \multirow{3}{*}{$\begin{array}{l}\text { GenBank } \\
\text { K00083 }\end{array}$} & \multirow{2}{*}{\multicolumn{2}{|c|}{ Untreated }} & \multicolumn{4}{|c|}{$\alpha \mathbf{G C}$} & \multicolumn{4}{|c|}{$\mathrm{OCH}$} & \multirow{2}{*}{\multicolumn{2}{|c|}{ Untreated }} & \multicolumn{4}{|c|}{$\alpha \mathbf{G C}$} & \multicolumn{3}{|c|}{$\mathrm{OCH}$} \\
\hline & & & & \multicolumn{2}{|c|}{$1.5 \mathrm{~h}$} & \multicolumn{2}{|c|}{$12 \mathrm{~h}$} & $1.5 \mathrm{~h}$ & & \multicolumn{2}{|c|}{$12 \mathrm{~h}$} & & & \multicolumn{2}{|c|}{$1.5 \mathrm{~h}$} & \multicolumn{2}{|c|}{$12 \mathrm{~h}$} & \multicolumn{2}{|c|}{$1.5 \mathrm{~h}$} & $12 \mathrm{~h}$ \\
\hline & & 1.0 & $P$ & 5.0 & $P$ & 0.3 & $P$ & 1.2 & $P$ & 0.1 & $P$ & 1.0 & $P$ & 4.0 & $P$ & 2.3 & $P$ & 0.7 & $P$ & $1.0 \mathrm{P}$ \\
\hline$I L-2$ & m16762 & 1.0 & $A$ & 391.4 & $P$ & 1.2 & A & 12.3 & $P$ & 1.3 & $A$ & 1.0 & A & 23.4 & $P$ & 0.2 & $A$ & 1.0 & A & $0.3 \mathrm{~A}$ \\
\hline$I L-2$ & K02292 & 1.0 & A & 129.6 & $\mathrm{P}$ & 0.6 & A & 32.8 & $A$ & 1.1 & $A$ & 1.0 & $A$ & 16.1 & $A$ & 0.7 & A & 10.7 & A & $1.5 \mathrm{~A}$ \\
\hline GM-CSF & X03020 & 1.0 & $P$ & 38.0 & $P$ & 0.4 & $A$ & 4.1 & $P$ & 0.1 & $A$ & 1.0 & $A$ & 15.7 & $P$ & 1.4 & $A$ & 2.7 & $A$ & $2.1 \mathrm{~A}$ \\
\hline IL-4 & X03532 & 1.0 & $P$ & 276.8 & $\mathrm{P}$ & 2.5 & $P$ & 47.3 & $P$ & 0.2 & $A$ & 1.0 & $A$ & 364.9 & $P$ & 35.1 & $P$ & 38.8 & $P$ & $4.7 \mathrm{P}$ \\
\hline IL-4 & M25892 & 1.0 & $P$ & 38.2 & $P$ & 0.2 & $P$ & 7.7 & $\mathrm{P}$ & 0.1 & $A$ & 1.0 & $\mathrm{P}$ & 69.6 & $P$ & 7.6 & $P$ & 9.1 & $P$ & $1.1 \mathrm{P}$ \\
\hline$I L-4$ & X03532 & 1.0 & A & 34.8 & $\mathrm{P}$ & 3.9 & A & 9.4 & $A$ & 1.9 & $A$ & 1.0 & A & 2.2 & A & 4.2 & A & 1.1 & A & $0.7 \mathrm{~A}$ \\
\hline$I L-13$ & M23504 & 1.0 & $A$ & 993.0 & $P$ & 1.4 & $A$ & 56.1 & $P$ & 1.8 & $A$ & 1.0 & $A$ & 140.7 & $P$ & 12.3 & $A$ & 19.1 & $A$ & $2.3 \mathrm{~A}$ \\
\hline$T N F-\alpha$ & D84196 & 1.0 & $P$ & 30.8 & $\mathrm{P}$ & 2.1 & $P$ & 1.7 & $\mathrm{P}$ & 1.2 & $P$ & 1.0 & $P$ & 16.5 & $P$ & 2.5 & $P$ & 1.8 & $P$ & $2.6 \mathrm{P}$ \\
\hline Lymphotoxin A & M16819 & 1.0 & $P$ & 6.9 & $P$ & 0.2 & A & 1.4 & $P$ & 0.1 & $A$ & 1.0 & $P$ & 2.5 & $P$ & 1.7 & $P$ & 1.2 & $P$ & $0.9 \mathrm{P}$ \\
\hline$I L-1 \alpha$ & M14639 & 1.0 & $P$ & 25.1 & $P$ & 5.6 & $P$ & 3.1 & $P$ & 4.4 & $\mathrm{P}$ & 1.0 & $\mathrm{P}$ & 6.7 & $P$ & 5.8 & $P$ & 1.1 & $P$ & $2.7 \mathrm{P}$ \\
\hline$I L-1 \beta$ & M15131 & 1.0 & $P$ & 8.0 & $P$ & 9.8 & $P$ & 1.3 & $\mathrm{P}$ & 7.9 & $P$ & 1.0 & $P$ & 3.3 & $P$ & 2.2 & $P$ & 0.6 & $P$ & $1.5 \mathrm{P}$ \\
\hline IL-1RA & L32838 & 1.0 & $P$ & 10.9 & $P$ & 15.2 & $P$ & 1.1 & $A$ & 11.3 & $P$ & 1.0 & $P$ & 5.3 & $P$ & 28.0 & $P$ & 0.9 & $P$ & $23.4 \mathrm{P}$ \\
\hline$I L-3$ & K01668 & 1.0 & A & 33.2 & $P$ & 2.6 & A & 4.7 & $A$ & 1.2 & $A$ & 1.0 & A & 4.0 & A & 1.1 & A & 1.4 & A & $1.7 \mathrm{~A}$ \\
\hline IL-6 & X54542 & 1.0 & A & 34.8 & $\mathrm{P}$ & 16.5 & $P$ & 8.8 & $\mathrm{P}$ & 10.7 & $\mathrm{P}$ & 1.0 & $A$ & 19.1 & $\mathrm{P}$ & 17.8 & $P$ & 1.8 & A & $12.2 \mathrm{~A}$ \\
\hline
\end{tabular}

Real-time PCR analyses were conducted for IFN- $\gamma$ and $I L-4$ as well as for other selected cytokine genes listed in Figure 4 (data not shown) to confirm the correlation with those obtained from microarray analysis. Each probe was assigned a "call" of present (P; expressed) or "absent" (A; not expressed) using the Affymetrix decision matrix. GenBank, GenBank accession number; IL-1RA, IL-1 receptor antagonist.

recently been shown to induce Th1-type activity superior to that induced by $\alpha G C$, and IL-12 is indispensable for the Th1-skewing effect of the analog (27), indicating the importance of IL-12 in augmenting IFN- $\gamma$ production in vivo $(14,28)$. Interestingly, the C-glycoside analog induces production of IFN- $\gamma$ and IL- 4 by NKT cells less strongly than does $\alpha \mathrm{GC}$ at 2 hours after in vivo administration. Given that $\alpha \mathrm{GC}$ and $\mathrm{C}$-glycoside analog have the same structure for their lipid tails, they might be expected to have comparable affinity for CD1d molecules, and the slightly "twirled" $\alpha$-anomeric galactose moiety between $\mathrm{C}$-glycoside and O-glycoside may modulate the agonistic effect of these glycolipids. Furthermore, the C-glycoside is more resistant to hydrolysis in vivo and may have an advantage for effective production of IL- 12 by APCs. In fact, $\mathrm{OCH}$ induces marginal IL-12 production after in vivo administration (data not shown), which makes it unable to induce IFN- $\gamma$ production by various cells. Therefore, the beneficial feature of $\mathrm{OCH}$ as an immunomodulator is that it does not trigger production of IFN- $\gamma$ in vivo.

As described previously, NKT cells recognize glycolipid antigens in the context of the nonpolymorphic MHC class I-like molecule CD1d (4). Crystal structure analysis revealed that the mouse CD1d molecule has a narrow and deep binding groove with extremely hydrophobic pockets, $A^{\prime}$ and $F^{\prime}(29)$. Thus the two aliphatic hydrocarbon chains would be captured by this binding groove of CD1d and the more hydrophilic galactose moiety of $\alpha \mathrm{GC}$ or $\mathrm{OCH}$ would be presented to TCR on NKT cells. As OCH is an analog of $\alpha \mathrm{GC}$ with a truncated sphingosine chain, it could be predicted that truncation of the hydrocarbon chain would make it more unstable on CD1d, which might then affect the duration of TCR stimulation on NKT cells. We demonstrated in this study that $\mathrm{OCH}$ detached from the CD1d molecule more rapidly than did $\alpha \mathrm{GC}$ after a shortterm pulse in which the glycolipids were segregated from the endosomal/lysosomal pathway. Accordingly, we showed that the initiation of IFN- $\gamma$ production by NKT cells required more prolonged TCR stimulation than was required for IL-4 production. Methods such as surface plasmon resonance were not appropriate for direct assessment of the interaction between glycolipids and CD1d, possibly because of unpredictable micelle formation and the poor solubility of glycolipids in aqueous solvents (30). The half-life of the interaction of glycolipids and CD1d was reported to be less than 1 minute by surface plasmon resonance (31), contradicting functional assays suggesting a much longer half-life. Therefore, we applied a biological assay to evaluate the stability of these glycolipids on CD1d molecules, as described previously (13).

The characteristics of $\mathrm{OCH}$ are somewhat analogous to those of an altered peptide ligand (APL) that has been shown to induce a subset of functional responses observed in intact peptide and, in some cases, induce production of selected cytokines by $\mathrm{T}$ cells (32-34). Thus, $\mathrm{OCH}$ and possibly other $\alpha \mathrm{GC}$ derivatives could be called "altered glycolipid ligands" (AGLs). Although the biological effects of APLs and AGLs could mediate a series of similar molecular events in target cells, it should be noted that APLs and AGLs differ in their "conceptual features." That is, APLs are usually altered in their amino acid residues to modify their affinity for TCRs, whereas AGLs have truncation of their hydrocarbon chain responsible for CD1d anchoring. This paper has highlighted the duration of NKT cell stimulation by CD1d-associated glycolipids as being a critical factor for determining the nature of AGLs for selective induction of cytokine production by NKT cells.

Given that IL-4 secretion consistently precedes IFN- $\gamma$ production by NKT cells after TCR ligation, we speculated there were critical differences in the upstream transcriptional requirements for the $I F N-\gamma$ and $I L-4$ genes in NKT cells. In support of this speculation, $\mathrm{CHX}$ treatment specifically inhibited the transcription of $I F N-\gamma$ but not that of $I L-4$. In contrast, transcription of both cytokines was abolished by CsA treatment, indicating that TCR-mediated activation of NF-AT is essential for the production of both cytokines. TCR signal-induced NF-AT activation occurs promptly corresponding to calcium influx (35). Meanwhile, the protein expression of specific 

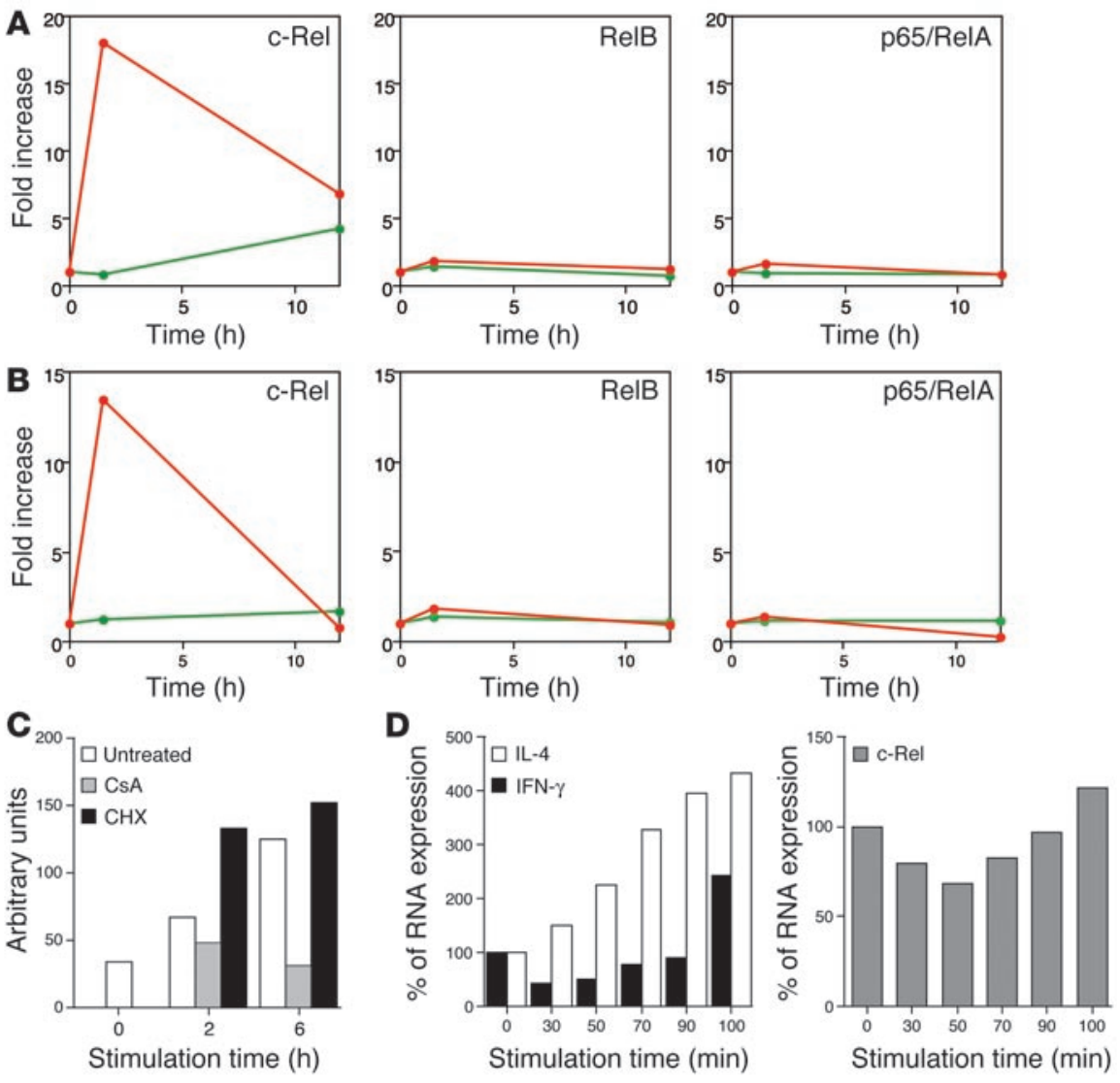

\section{Figure 5}

Induction of NF- $\mathrm{KB}$ family members in activated NKT cells. (A) Plotted values represent data of Affymetrix microarray analysis for the indicated genes. The $\alpha \mathrm{GC}$-stimulated (red lines) or $\mathrm{OCH}$-stimulated (green lines) cells as well as unstimulated liver NKT cells were analyzed at the same time points and the data are presented as the relative value for stimulated NKT cells when the value in NKT cells derived from untreated animals was defined as 1. (B) Realtime PCR analysis for the same genes as in A. Data are presented as described in Figure 4. (C) Sorted liver NKT cells were pretreated with $\mathrm{CsA}$ or $\mathrm{CHX}$ and were stimulated with immobilized $m A b$ to $C D 3$, and comparative values of $\mathrm{c}-\mathrm{Rel}$ transcripts relative to GAPDH were determined. (D) Sorted liver NKT cells were stimulated with immobilized $\mathrm{mAb}$ to $\mathrm{CD} 3$ for the indicated periods of time and then were cultured without stimulation for up to a total of 120 minutes after the initial stimulation. Total RNA was extracted from each sample and analyzed for relative amounts of transcripts of IFN- $\gamma$ or IL-4 (left), or $c-R e l$ (right). The amount of RNA derived from unstimulated NKT cells was defined as $100 \%$.

tion and DNA binding, most of the nuclear c-Rel induced after $T$ cell stimulation has been shown to be derived from newly translated c-Rel proteins. In contrast, pre-existing c-Rel scarcely translocates to the nucleus at transcription factors takes more time to accomplish. The requirement for prolonged TCR stimulation for initiation of IFN- $\gamma$ transcription may be due to its dependency on specific gene expression.

Recently, Matsuda et al. have shown using cytokine reporter mice that V $\alpha 14$-invariant NKT cells express cytokine transcripts in the resting state, but express protein only after stimulation (22). We obtained a similar result with our microarray analysis, in that many cytokine transcripts including IFN- $\gamma$ and IL-4 were detectable in unstimulated NKT cells derived from liver or spleen, because most of them were assigned a "call" of "present" by the Affymetrix decision matrix, which means they were significantly expressed. The mechanism of translation of pre-existing cytokine transcripts after activation of NKT cells remains to be investigated.

Through microarray analysis and real-time PCR, we next identified a member of the NF- $\mathrm{kB}$ family of transcription factors, c-Rel, as being a protein rapidly expressed after $\alpha \mathrm{GC}$ treatment and possibly responsible for the transcription of IFN- $\gamma$. Treatment with $\alpha \mathrm{GC}$ selectively upregulated $c$-Rel transcription 1.5 hours after stimulation of NKT cells in vivo. OCH treatment, however, showed no induction of $c$-Rel transcription. Although $c$-Rel is transcriptionally upregulated after TCR stimulation of T cells (36), transcription of other NF-кB family members such as p65/RelA, RelB, $N F-\kappa B 1$, and $N F-\kappa B 2$ was unchanged (data not shown). CsA treatment inhibited c-Rel transcription, but CHX did not, indicating that inducible transcription of c-Rel was directly controlled by TCR signal-mediated activation of NF-AT, which is consistent with a previous report (19). Although the pre-existing NF-אB proteins in general provide a means of rapidly altering cellular responses by inducing the destruc-

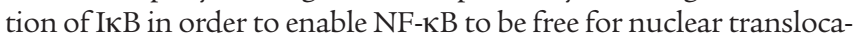

all (36), indicating that the nuclear induction of c-Rel in T lymphocyte requires ongoing protein synthesis. The retrovirally transduced loss-of-function mutant c-Rel (c-Rel $\Delta \mathrm{TA})$ significantly inhibited transcription of IFN- $\gamma$ genes, indicating the crucial role of c-Rel in their transcription after activation of NKT cells. Although it is possible that the Rel domain of the dominant negative mutant may affect a number of NF- $\kappa B$ dimers, it is unlikely, because IFN- $\gamma$ production by stimulated NKT cells were CHX sensitive and other NK-кB members were not induced after stimulation in the microarray analysis. in slightly augmented expression of IFN- $\gamma$ after stimulation. Induction of endogenous c-Rel after in vitro stimulation might reduce the effect of retrovirally introduced c-Rel protein.

Whereas c-Rel has been associated with the functions of various cell types, its role in the immune system was first demonstrated in its involvement in $I L-2$ transcription (37), in which it possibly induced chromatin remodeling of the promoter (38). Recently, the promoters for the genes encoding $I L-3, I L-5, I L-6, T N F-\alpha, G M-C S F$, and IFN- $\gamma$ were shown to contain $\kappa B$ sites or the $\kappa B$-related CD28RE. Gene targeting of $c$-Rel in mice revealed that $c$-Rel-deficient $\mathrm{T}$ cells have a defect in the production of IL-2, IL-3, IL-5, GM-CSF, TNF- $\alpha$, and IFN- $\gamma$, although expression of some of the cytokines was rescued by the addition of exogenous IL-2 $(39,40)$. Regarding the involvement of c-Rel in IFN- $\gamma$ production, the c-Rel inhibitor pentoxyfylline (41) selectively suppresses Th1 cytokine production and EAE induction (42), and transgenic mice expressing the trans-dominant form of I $\mathrm{B} \alpha$ have a defect in IFN- $\gamma$ production and the Th1 response (43). Recently, an elegant study using $c$-Rel-deficient mice revealed $c$-Rel has crucial roles in IFN- $\gamma$ production by activated $T$ cells and conseRetroviral transduction of wild-type c-Rel into NKT cells resulted 
A

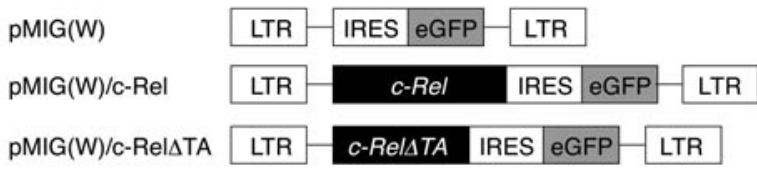

B

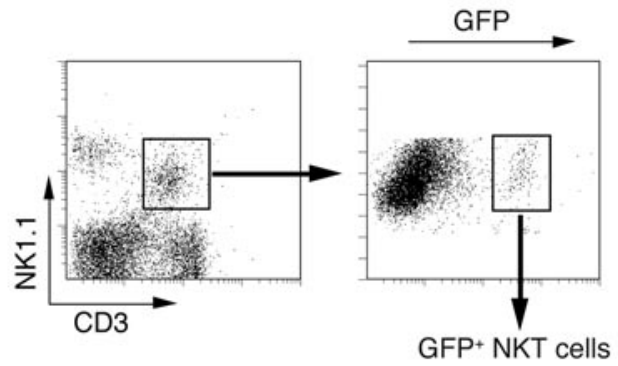

C

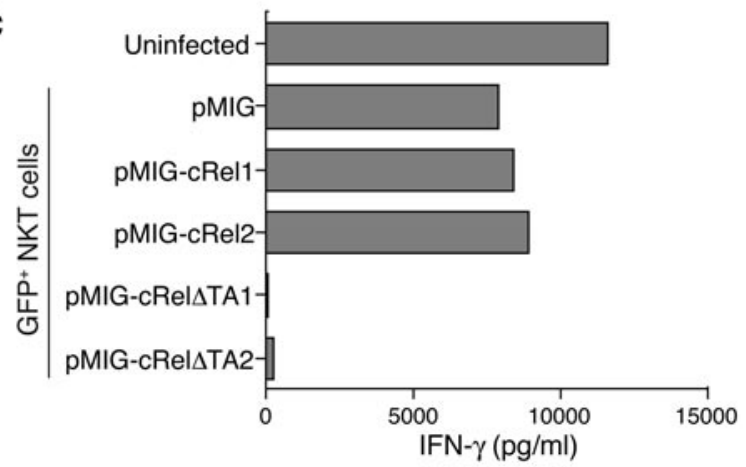

quent Th1 development by affecting the cellular functions of both $\mathrm{T}$ cells and APCs (20).Thus, the critical involvement of c-Rel for IFN- $\gamma$ production in NKT cells is consistent with these findings.

Our results indicate that rapid calcium influx and subsequent NF-AT activation is essential for IFN- $\gamma$ production by activated NKT

\section{Figure 6}

Cytokine production after retroviral transduction of c-Rel or c-Rel $\Delta \mathrm{TA}$ into NKT cells. (A) DNA fragments encoding wild-type c-Rel or its mutant were cloned into the pMIG(W) bicistronic retrovirus vector. The mutant form of c-Rel (c-Rel $\Delta T A$ ) lacks the transactivation domain of the c-Rel protein. LTR, long terminal repeat; IRES, internal ribosome entry site; eGFP, enhanced GFP. (B) Flow cytometric identification of cells transfected with the viral vector. Among the NK1.1+CD3 ${ }^{+}$liver NKT cells identified in the left panel, approximately $10 \%$ were GFP positive. The GFP-positive NKT cells were sorted for further analysis. (C) IFN- $\gamma$ production by NKT cells transfected with c-Rel or its dominant negative mutant. The CD3+NK1.1+ NKT cells infected with the viruses were isolated based on their expression of GFP and were stimulated with immobilized $m A b$ to CD3. For transduction of $c-R e l$ or $c-R e l \Delta T A$ into NKT cells, two independent clones of each retroviral vector were used. The level of IFN- $\gamma$ in the supernatants was measured by ELISA.

cells and that c-Rel plays a crucial role in IFN- $\gamma$ production as well. NF-AT shows quick and sensitive nucleocytoplasmic shuttling after TCR activation (35). Feske et al. demonstrated that the pattern of cytokine production by $\mathrm{T}$ cells was determined by the duration of nuclear residence of NF-AT (44) and that sustained NF-AT signaling promoted IFN- $\gamma$ expression in $\mathrm{CD}^{+} \mathrm{T}$ cells (45). Considering the structural feature of $\alpha \mathrm{GC}$ with longer lipid chain, sustained stimulation by $\alpha \mathrm{GC}$ induces long-lasting calcium influx, resulting in sustained nuclear residence of NF-AT, and c-Rel protein synthesis, which enables NKT cells to produce IFN- $\gamma$. In contrast, the rather sporadic stimulation by $\mathrm{OCH}$ induces short-lived nuclear residence of NF-AT, followed by marginal c-Rel expression, which leaves NKT cells unable to produce IFN- $\gamma$ (Figure 7). Thus, the kinetic and quantitative differences between $\alpha \mathrm{GC}$ and $\mathrm{OCH}$ in the induction of transcription factors, such as NF-AT and c-Rel, determine the pattern of cytokine production by NKT cells. As CD1d molecules are nonpolymorphic and are remarkably well conserved among the species, the preferential induction of IL-4 production through NKT activa-

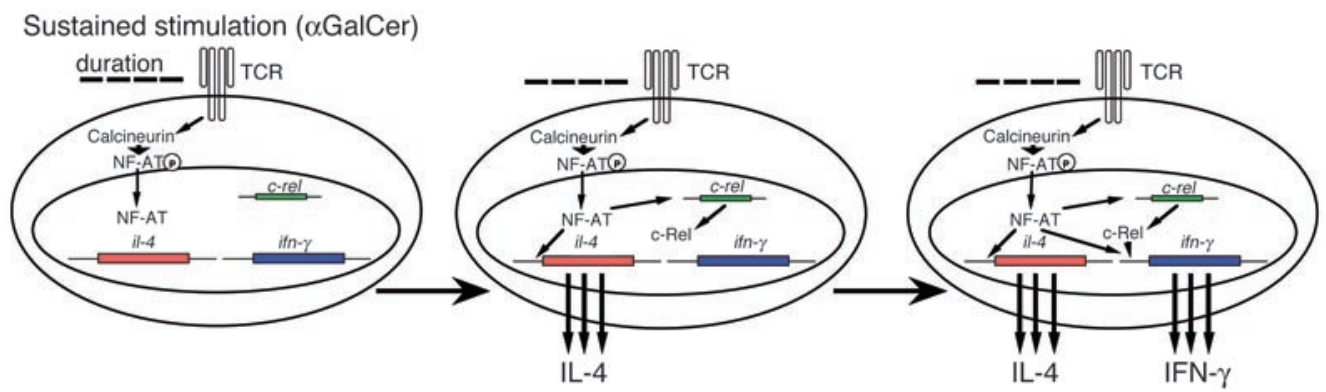

Sporadic stimulation $(\mathrm{OCH})$

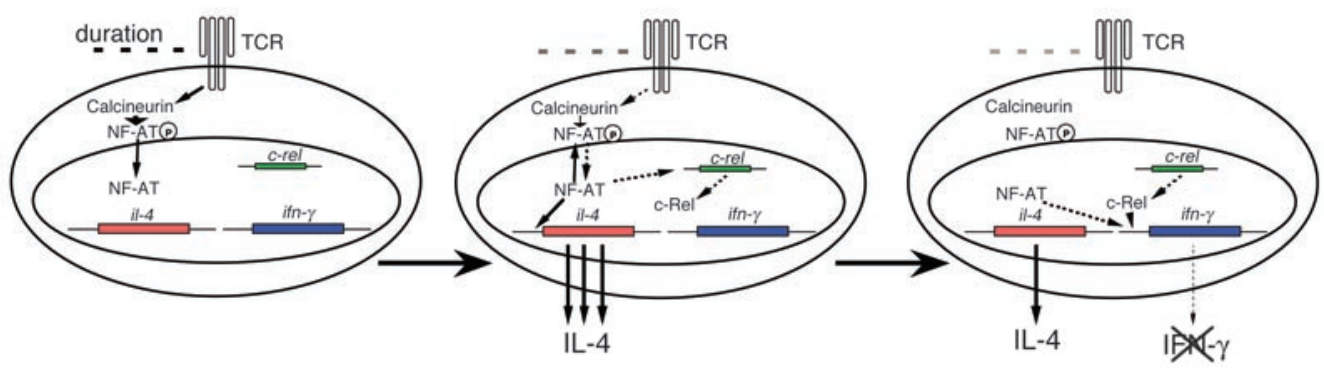

Figure 7

A model for the differential expression of IFN- $\gamma$ and IL-4 after treatment of NKT cells with $\alpha \mathrm{GC}$ or OCH. See text for details. 
tion and subsequent Th2 polarization suggest that $\mathrm{OCH}$ may be an attractive therapeutic reagent to use for Th1-mediated autoimmune diseases such as multiple sclerosis and rheumatoid arthritis.

\section{Acknowledgments}

We thank Kyoko Hayakawa and Sebastian Joyce for providing the cell lines; Thomas Grundström for providing the c-Rel plasmid; and Luk Van Parijs for providing the retroviral vectors and packaging vector. We also thank Miho Mizuno and Chiharu Tomi for excellent technical assistance; and Yuki Kikai for cell sorting. We are grateful to John Ludvic Croxford for critical reading of the manuscript. This work was supported by the
Organization for Pharmaceutical Safety and Research, Grantin-Aid for Scientific Research (B) 14370169 from Japan Society for the Promotion of Science, Mochida Memorial Foundation, and Uehara Memorial Foundation.

Received for publication December 18, 2003, and accepted in revised form April 6, 2004.

Address correspondence to: Sachiko Miyake, Department of Immunology, National Institute of Neuroscience, NCNP, 4-1-1 Ogawahigashi, Kodaira, Tokyo 187-8502, Japan. Phone: 81-42341-2711; Fax: 81-42-346-1753; E-mail: miyake@ncnp.go.jp.
1. Kronenberg, M., and Gapin, L. 2002. The unconventional lifestyle of NKT cells. Nat. Rev. Immunol. 2:557-568.

2. Taniguchi, M., Harada, M., Kojo, S., Nakayama, T., and Wakao, H. 2003. The regulatory role of Vo14 NKT cells in innate and acquired immune response. Annu. Rev. Immunol. 21:483-513.

3. Brossay, L., et al. 1998. CD1d-mediated recognition of an $\alpha$-galactosylceramide by natural killer $\mathrm{T}$ cells is highly conserved through mammalian evolution. J. Exp. Med. 188:1521-1528.

4. Kawano, T., et al. 1997. CD1d-restricted and TCRmediated activation of vo14 NKT cells by glycosylceramides. Science. 278:1626-1629.

5. Spada, F.M., et al. 1998. CD1d-restricted recognition of synthetic glycolipid antigens by human natural killer T cells. J. Exp. Med. 188:1529-1534.

6. Carnaud, C., et al. 1999. Cross-talk between cells of the innate immune system: NKT cells rapidly activate NK cells. J. Immunol. 163:4647-4650.

7. Fujii, S.I., Shimizu, K., Smith, C., Bonifaz, L., and Steinman, R.M. 2003. Activation of natural killer $\mathrm{T}$ cells by $\alpha$-galactosylceramide rapidly induces the full maturation of dendritic cells in vivo and thereby acts as an adjuvant for combined CD4 and CD8 T cell immunity to a coadministered protein. J. Exp. Med. 198:267-279.

8. Chiba, A., et al. 2004. Suppression of collageninduced arthritis by natural killer $\mathrm{T}$ cell activation with $\mathrm{OCH}$, a sphingosine-truncated analog of $\alpha$-galactosylceramide. Arthritis Rheum. 50:305-313.

9. Miyamoto, K., Miyake, S., and Yamamura, T. 2001. A synthetic glycolipid prevents autoimmune encephalomyelitis by inducing TH2 bias of natural killer T cells. Nature. 413:531-534.

10. Burdin, N., et al. 1998. Selective ability of mouse CD1 to present glycolipids: $\alpha$-galactosylceramide specifically stimulates $V \alpha 14+$ NK T lymphocytes. J. Immunol. 161:3271-3281.

11. De Silva, A.D., et al. 2002. Lipid protein interactions: the assembly of CD1d1 with cellular phospholipids occurs in the endoplasmic reticulum. J. Immunol. 168:723-733.

12. Antonsson, A., Hughes, K., Edin, S., and Grundstrom, T. 2003. Regulation of c-Rel nuclear localization by binding of $\mathrm{Ca} 2+/$ calmodulin. Mol. Cell. Biol. 23:1418-1427.

13. Moody, D.B., et al. 2002. Lipid length controls antigen entry into endosomal and nonendosomal pathways for CD1b presentation. Nat. Immunol. 3:435-442.

14. Fujii, S., Shimizu, K., Kronenberg, M., and Steinman, R.M. 2002. Prolonged IFN- $\gamma$-producing NKT response induced with $\alpha$-galactosylceramide-loaded DCs. Nat. Immunol. 3:867-874.

15. Akbari, O., et al. 2003. Essential role of NKT cells producing IL-4 and IL-13 in the development of allergen-induced airway hyperreactivity. Nat. Med. 31:31.

16. Heller, F., Fuss, I.J., Nieuwenhuis, E.E., Blumberg, R.S., and Strober, W. 2002. Oxazolone colitis, a Th2 colitis model resembling ulcerative colitis, is mediated by IL-13-producing NK-T cells. Immunity. 17:629-638.

17. Leite-de-Moraes, M.C., et al. 2002. Ligand-activated natural killer $\mathrm{T}$ lymphocytes promptly produce IL-3 and GM-CSF in vivo: relevance to peripheral myeloid recruitment. Eur. J. Immunol. 32:1897-1904.

18. Chen, H., Huang, H., and Paul, W.E. 1997. NK1.1+ CD4+ T cells lose NK1.1 expression upon in vitro activation. J. Immunol. 158:5112-5119.

19. Venkataraman, L., Burakoff, S.J., and Sen, R. 1995. FK506 inhibits antigen receptor-mediated induction of c-rel in B and T lymphoid cells. J. Exp. Med. 181:1091-1099.

20. Hilliard, B.A., et al. 2002. Critical roles of c-Rel in autoimmune inflammation and helper $\mathrm{T}$ cell differentiation. J. Clin. Invest. 110:843-850. doi:10.1172/JCI200215254.

21. Carrasco, D., et al. 1998. Multiple hemopoietic defects and lymphoid hyperplasia in mice lacking the transcriptional activation domain of the c-Rel protein. J. Exp. Med. 187:973-984.

22. Matsuda, J.L., et al. 2003. Mouse V $\alpha 14$ i natural killer $\mathrm{T}$ cells are resistant to cytokine polarization in vivo. Proc. Natl. Acad. Sci. U. S. A. 100:8395-8400.

23. Tsytsykova, A.V., Tsitsikov, E.N., and Geha, R.S. 1996. The CD40L promoter contains nuclear factor of activated $T$ cells-binding motifs which require $\mathrm{AP}-1$ binding for activation of transcription. J. Biol. Chem. 271:3763-3770.

24. Parra, E., Mustelin, T., Dohlsten, M., and Mercola, D. 2001. Identification of a CD28 response element in the CD40 ligand promoter. J. Immunol. 166:2437-2443.

25. Kitamura, H., et al. 1999. The natural killer T (NKT) cell ligand $\alpha$-galactosylceramide demonstrates its immunopotentiating effect by inducing interleukin (IL)-12 production by dendritic cells and IL-12 receptor expression on NKT cells. J. Exp. Med. 189:1121-1128.

26. Smyth, M.J., et al. 2002. Sequential production of interferon- $\gamma$ by NK1.1 ${ }^{+} \mathrm{T}$ cells and natural killer cells is essential for the antimetastatic effect of $\alpha$-galactosylceramide. Blood. 99:1259-1266.

27. Schmieg, J., Yang, G., Franck, R.W., and Tsuji, M. 2003. Superior protection against malaria and melanoma metastases by a C-glycoside analogue of the natural killer $\mathrm{T}$ cell ligand $\alpha$-galactosylceramide. J. Exp. Med. 198:1631-1641.

28. Brigl, M., Bry, L., Kent, S.C., Gumperz, J.E., and Brenner, M.B. 2003. Mechanism of CD1d-restricted natural killer $\mathrm{T}$ cell activation during microbial infection. Nat. Immunol. 4:1230-1237.

29. Zeng, Z., et al. 1997. Crystal structure of mouse CD1: An MHC-like fold with a large hydrophobic binding groove. Science. 277:339-345.

30. Cantu, C., 3rd, Benlagha, K., Savage, P.B., Bendelac, A., and Teyton, L. 2003. The paradox of immune molecular recognition of $\alpha$-galactosylceramide: low affinity, low specificity for CD1d, high affinity for $\alpha \beta$ TCRs. J. Immunol. 170:4673-4682.

31. Benlagha, K., Weiss, A., Beavis, A., Teyton, L., and
Bendelac, A. 2000. In vivo identification of glycolipid antigen-specific $\mathrm{T}$ cells using fluorescent CD1d tetramers. J. Exp. Med. 191:1895-1903.

32. Evavold, B.D., and Allen, P.M. 1991. Separation of IL-4 production from Th cell proliferation by an altered $\mathrm{T}$ cell receptor ligand. Science. 252:1308-1310.

33. Chaturvedi, P., Yu, Q., Southwood, S., Sette, A., and Singh, B. 1996. Peptide analogs with different affinities for MHC alter the cytokine profile of T helper cells. Int. Immunol. 8:745-755.

34. Boutin, Y., Leitenberg, D., Tao, X., and Bottomly, K. 1997. Distinct biochemical signals characterize agonist- and altered peptide ligand-induced differentiation of naive CD4+ T cells into Th1 and Th2 subsets. J. Immunol. 159:5802-5809.

35. Zhu, J., and McKeon, F. 2000. Nucleocytoplasmic shuttling and the control of NF-AT signaling. Cell. Mol. Life Sci. 57:411-420.

36. Venkataraman, L., Wang, W., and Sen, R. 1996. Differential regulation of c-Rel translocation in activated B and T cells. J. Immunol. 157:1149-1155.

37. Ghosh, P., Tan, T.H., Rice, N.R., Sica, A., and Young, H.A. 1993. The interleukin 2 CD28-responsive complex contains at least three members of the NF $\kappa$ B family: c-Rel, p50, and p65. Proc. Natl. Acad. Sci.U. S. A. 90:1696-1700.

38. Rao, S., Gerondakis, S., Woltring, D., and Shannon, M.F. 2003. c-Rel Is required for chromatin remodeling across the IL-2 gene promoter. J. Immunol. 170:3724-3731.

39. Gerondakis, S., et al. 1996. Rel-deficient T cells exhibit defects in production of interleukin 3 and granulocyte-macrophage colony-stimulating factor. Proc. Natl. Acad. Sci. U. S. A. 93:3405-3409.

40. Kontgen, F., et al. 1995. Mice lacking the c-rel proto-oncogene exhibit defects in lymphocyte proliferation, humoral immunity, and interleukin-2 expression. Genes Dev. 9:1965-1977.

41. Wang, W., Tam, W.F., Hughes, C.C., Rath, S., and Sen, R. 1997. c-Rel is a target of pentoxifyllinemediated inhibition of $\mathrm{T}$ lymphocyte activation. Immunity. 6:165-174.

42. Rott, O., Cash, E., and Fleischer, B. 1993. Phosphodiesterase inhibitor pentoxifylline, a selective suppressor of T helper type 1- but not type 2-associated lymphokine production, prevents induction of experimental autoimmune encephalomyelitis in Lewis rats. Eur. J. Immunol. 23:1745-1751.

43. Aronica, M.A., et al. 1999. Preferential role for NF- $\mathrm{K}$ B/Rel signaling in the type 1 but not type $2 \mathrm{~T}$ cell-dependent immune response in vivo. J. Immunol. 163:5116-5124.

44. Feske, S., Draeger, R., Peter, H.H., Eichmann, K., and Rao, A. 2000. The duration of nuclear residence of NFAT determines the pattern of cytokine expression in human SCID T cells. J. Immunol. 165:297-305.

45. Porter, C.M., and Clipstone, N.A. 2002. Sustained NFAT signaling promotes a Th1-like pattern of gene expression in primary murine CD4+ T cells. J. Immunol. 168:4936-4945. 